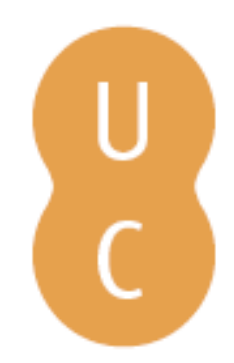

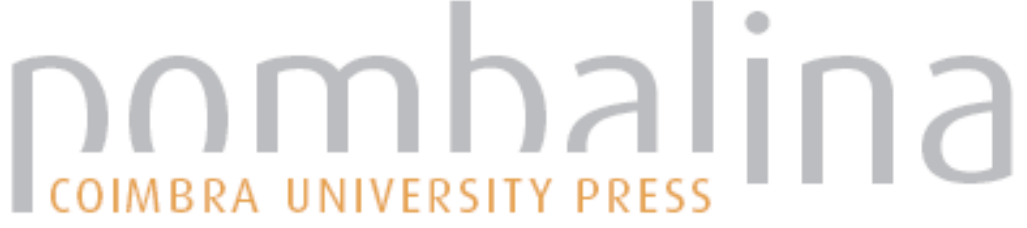

\section{The role of forest fires in land use/land cover changes in Portugal}

Autor(es): $\quad$ Parente, Joana; Pereira, Mário G.; Tonini, Marj

Publicado por: Imprensa da Universidade de Coimbra

URL

persistente:

URI:http://hdl.handle.net/10316.2/44591

DOI:

DOI:https://doi.org/10.14195/978-989-26-16-506_74

Accessed : $\quad$ 26-Apr-2023 01:02:54

A navegação consulta e descarregamento dos títulos inseridos nas Bibliotecas Digitais UC Digitalis, UC Pombalina e UC Impactum, pressupõem a aceitação plena e sem reservas dos Termos e Condições de Uso destas Bibliotecas Digitais, disponíveis em https://digitalis.uc.pt/pt-pt/termos.

Conforme exposto nos referidos Termos e Condições de Uso, o descarregamento de títulos de acesso restrito requer uma licença válida de autorização devendo o utilizador aceder ao(s) documento(s) a partir de um endereço de IP da instituição detentora da supramencionada licença.

Ao utilizador é apenas permitido o descarregamento para uso pessoal, pelo que o emprego do(s) título(s) descarregado(s) para outro fim, designadamente comercial, carece de autorização do respetivo autor ou editor da obra.

Na medida em que todas as obras da UC Digitalis se encontram protegidas pelo Código do Direito de Autor e Direitos Conexos e demais legislação aplicável, toda a cópia, parcial ou total, deste documento, nos casos em que é legalmente admitida, deverá conter ou fazer-se acompanhar por este aviso. 


\section{ADVANCES IN}

\section{FOREST FIRE RESEARCH}

\section{8}

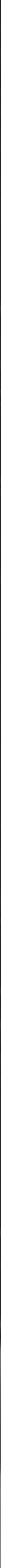




\title{
The role of forest fires in land use/land cover changes in Portugal
}

\author{
Joana Parente $^{1 *}$; Mário G. Pereira ${ }^{1,2}$; Marj Tonini ${ }^{3}$ \\ ${ }^{1}$ Centro de Investigação e Tecnologias Agroambientais e Biológicas, Universidade de Trás-os- \\ Montes e Alto Douro, Quinta de Prados, 5000-801 Vila Real, Portugal, \{joanaparente@utad.pt*; \\ gpereira@utad.pt\} \\ ${ }^{2}$ Instituto Dom Luiz, Faculdade de Ciências da Universidade de Lisboa, Lisboa, Portugal \\ ${ }^{3}$ Institute of Earth Surface Dynamics, Faculty of Geosciences and Environment, University of \\ Lausanne, Lausanne, Switzerland, \{marj.tonini@unil.ch\}
}

\begin{abstract}
In the last decades, Portugal registered substantial land use / land cover changes (LULCC) driven by the abandonment of rural areas, fast urbanization, and expansion of metropolitan areas and costal touristic centers motivated by the significant socio-economic development. Consequently, there significant transitions incurred among different land use classes as well as a homogenization of the fuel bands, increasing the extension and complexity of fire prone areas. Portugal was particularly affected by forest fires (FF) with more than 18,000 FF/year and annual burnt area (BA) of $107,000 \mathrm{ha} /$ year since 1980, while the average size of such events has increased from 4 ha to 13 ha in the last 10 years. This study analysed the FF occurred in continental Portugal between 1990 and 2013, with the main focus on: (i) assess the global and regional differences/similarities in LULCC and fire regime; (ii) evaluating the role of FF on LULCC and; (iii) to provide a better understanding (identification and characterization) of space-time cluster distribution of FF. We used the following datasets: (i) land use/land cover inventories from CORINE; (ii) BA polygons from the Portuguese Institute for the Conservation of Nature and Forests. A geospatial methodological approach, based on GIS analyses, was developed to identify LULCC and to characterize the impact of FFs on these changes; then, cluster analyses were performed to examine patterns in FFs distribution and, finally, to discover how landscape factors control FF clusters. This research provides a quantitative assessment of the relationship between LULCC and FFs in Portugal. The authors believe that the obtained results provide a valuable contribution to: (i) characterize the LULCC in Portugal; (ii) assess the role of FFs on LULCC; (iii) support a better landscape management to reduce related losses of life, property and assets; as well as, (iv) promote educational events to increase public awareness to the causes and consequences of FF.
\end{abstract}

Keywords: Land use/Land Cover changes, Forest fires, Portugal, Cluster analysis

\section{Introduction}

In the last decades, Continental Portugal registered substantial land use and land cover changes (LULCC) driven by the abandonment of rural areas, fast urbanization, expansion of metropolitan areas and costal touristic centers motivated by the significant socio-economic development (Pereira et al. 2014; Tonini et al. 2018). Consequently, there were significant changes in land-use and vegetation cover, as well as a homogenization of the fuel bands, increasing the extension and complexity of fire risk areas (Amato et al. 2018). Portugal was particularly affected by forest fires (FF) with more than $18,000 \mathrm{FF} /$ year and burnt area (BA) of 107,000 ha/year since 1980, while the average size of such events has increased from 4 ha to 13 ha in the last 10 years (San-Miguel-Ayanz et al. 2016). These fires caused a wide range of environmental, economic and human damages, including personal injury and death as well as a large amount of BA (Parente, Pereira, Amraoui, and Fischer 2018; Tedim et al.

Advances in Forest Fire Research 2018 - Page 670 
2018). The high fire incidence in Continental Portugal has been associated with several factors such as: (i) the Mediterranean climate type, characterized by conditions conducive to the development of vegetation in the cold and humid season and the dryness of life and dead fuels during the dry and hot season (Kanevski and Pereira 2017; Parente, Pereira, Amraoui, and Tedim 2018); (ii) the occurrence of weather and climatic extremes, such as heat waves (Parente, Pereira, Amraoui, and Fischer 2018) associated with anomalous atmospheric circulation patterns (Pereira et al. 2005; Amraoui et al. 2015) and episodes of drought (Bastos et al. 2011; Gouveia et al. 2012); as well as (iii) forestry, LULCC and socioeconomic characteristics and trends (Pereira et al. 2015; Parente et al. 2016). The present study analyse the FF occurrence in Continental Portugal between 1990 and 2016, with the main focus on: (i) the assessment of global and regional differences/similarities in LULCC and fire regime; (ii) the role of FF on LULCC; (iii) a better understanding (identification and characterization) of space-time cluster distribution of FF.

\section{Dataset and Methodology}

\subsection{Study area}

Portugal mainland has a surface area of $90,000 \mathrm{~km}^{2}$ and is located in the Iberian Peninsula, between Spain and Atlantic Ocean. The temperate or Mediterranean type of climate of the country provides dry and warm summers in the north and dry and hot summers in the south (Rubel and Kottek 2010). These climatic conditions promote the vegetation growth during spring and thermal and hydric stress during summer. Extreme weather favours the occurrence of FF in specific periods and other environmental characteristics (e.g., topography, land use / land cover) drive the spatial distribution of FF.

\subsection{Land use / land cover dataset}

LULCC information were gather from the 2000-2006 and 2006-2012 CORINE Land Cover Changes (CLCC) inventory (Figure 1, https://land.copernicus.eu/pan-european/corine-land-cover), which is based on image-to-image comparison of two CLC consecutive inventories which have a minimum cartographic unit of 5 ha and a thematic accuracy greater than $85 \%$.

\subsection{Forest fire dataset}

BA polygons were obtained from National Mapping Burnt Area dataset available in vector format from 1990 to 2017 and provide by the Portuguese Institute for the Conservation of Nature and Forests (http://www2.icnf.pt/portal/florestas/dfci/inc/info-geo). As this study is focused on the two most recent vector maps of CLCC inventory, we selected the BA polygons between 2000 to 2007 and 2006 to 2013. Since one of the main objectives of this study is to evaluate the influence of spatial-temporal clusters (obtained in Parente et al. (2016)), on the CLCC, the events of these two periods were split into three BA classes as in Parente et al. (2016). The final datasets for each period and for each BA classes include: (i) 3,893 (3,227) FFs for the 2000 - 2007 (2006 - 2013) period for 5 ha $\leq$ BA $<15$ ha class, which corresponds to a total BA of $35,874(28,703)$ ha; (ii) $4,518(3,534)$ FFs for the $2000-2007(2006-2013)$ period for 15 ha $\leq$ BA $<100$ ha class, which corresponds to a total BA of 173,914.3 (139,180) ha; and, (iii) 1,687 (1,139) FFs for the $2000-2007(2006-2013)$ period for $\mathrm{BA} \geq 100$ ha class, which corresponds to a total BA of 1,176,291 $(512,083)$ ha.

\subsection{Methodology}

A geospatial approach, based on GIS analysis, was developed to identify LULCC, and to characterize the impact of FFs on these changes; then, cluster analyses performed in Parente $e t$ al. (2016) was used to examine patterns in FFs distribution and, finally, to discover how factors as climate, soil, distributed vegetation, human activities and infrastructures control FF clusters. 

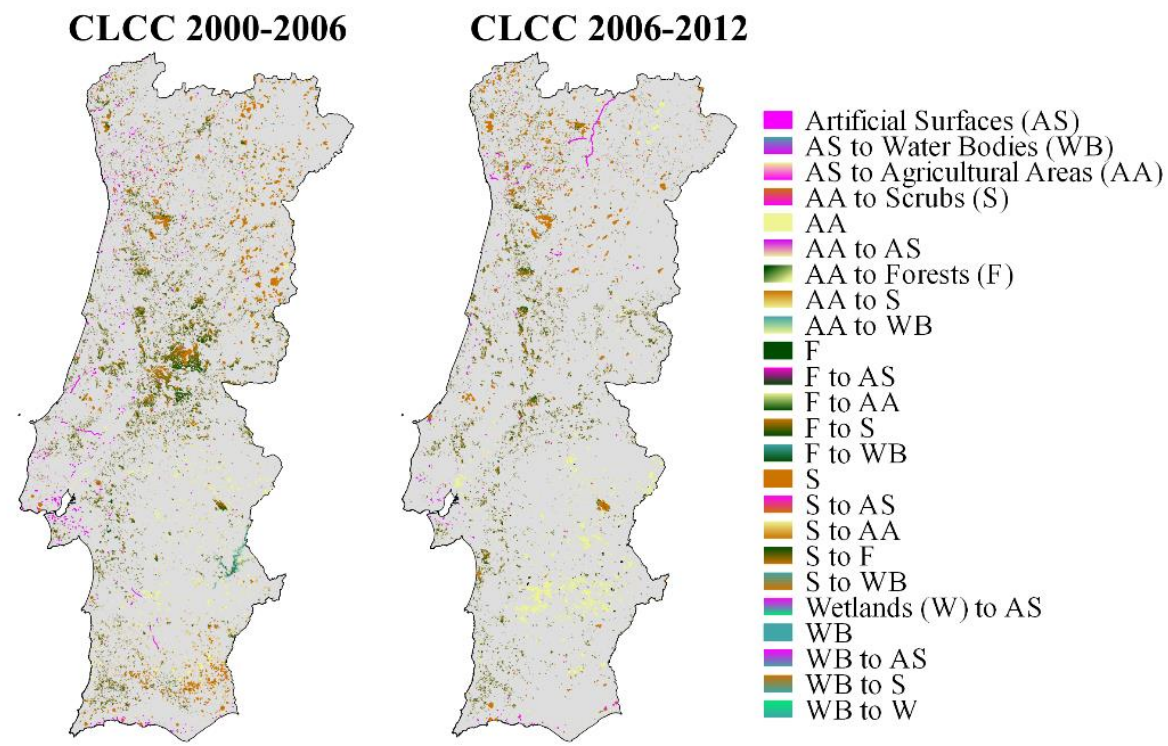

Figure 1 - CORINE land cover changes (CLCC) inventory for 2000-2006 and 2006-2012.

\section{Results}

\subsection{GIS analysis}

GIS analysis performed to CLCC inventories and BA polygons datasets for each period unveil that: (i) $9 \%$ of CLC 2000 and $6 \%$ of CLC 2006 total area have changed; (ii) the fraction of total BA within the areas of LULCC was 25\% between 2000 and 2007, with higher values in 2003, 2005 and 2006, but decrease to $13 \%$ in the $2006-2013$ period, when 2006 was the year with maximum BA in the LULCC areas. It is important to underline the role of the BA in 2006, 2007 and 2013 in the CLCC between 2000-2006 and 2006-2012. In relation to the total annual BA in each year, the BA2006 CLCC2000-2006 is 30\%, BA2007คCLCC2000-2006 is 8\%, BA2006 $C L C C 2006-2012$ is $33 \%$ and BA2013 $\cap$ CLCC2006-2012 is $8 \%$. This suggests that BA2006 may have played an important role in both CLCC2000-2006 and CLCC2006-2012, which is consistent with the fact that CLC inventories have a minimum time consistency of plus/minus one year. On the other hand, the interception of BA2007 and BA2013, respectively, with CLCC2000-2006 and CLCC2006-2012 is only $8 \%$, which corresponds to the minimum values of BA $\cap C L C C$ in each period. These results are even more relevant if it is took into account that BA2006 and BA2007 are, respectively, the third and second lowest annual BA values, only accounting for 3.7\% and $2.0 \%$ of total BA between 2000 and 2013 while, in the same period, BA2013 is the third highest annual BA value.

Obtained results also disclose that (iii) Forest and semi natural areas was the CLC class with more BA, namely 52\% in CLCC 2000 - 2006 and 21\% in CLCC 2006 - 2012. The spatial distribution of the LULCC was not uniform; in fact, (iv) in the 2000 - 2006 period, most of the BA within the CLCC is concentrated in central Portugal, mainly in due to the BA of 2003, while for 2006-2012,

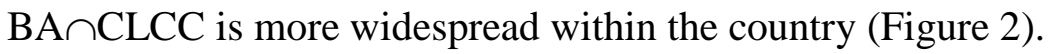



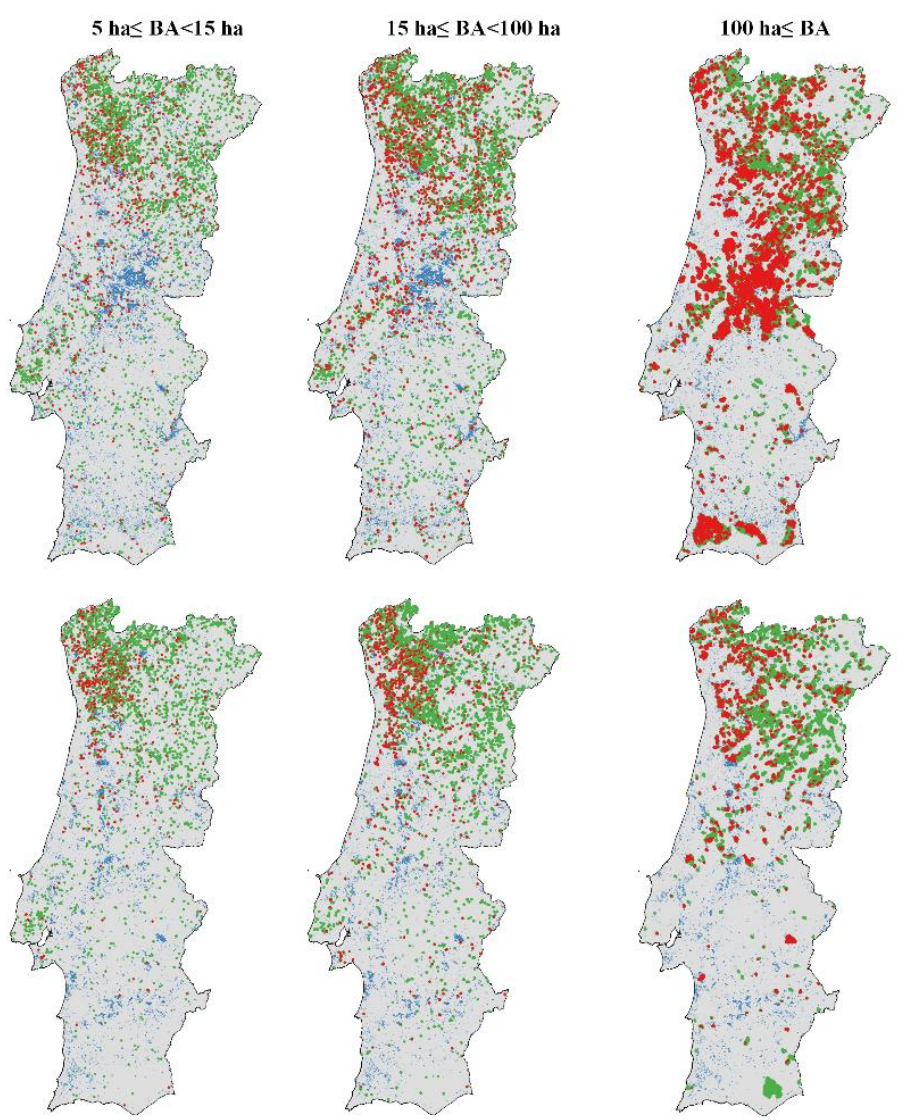
CORINE land cover changes (CLCC)
Burnt area (BA)
BA within CLCC

Figure 2 - CORINE land cover changes (CLCC) inventory, Burnt area $(B A)$ and BA included within the CLCC for the period 2000-2006 (top panel) and 2006-2012 (bottom panel)

\subsection{Cluster analysis}

The cluster analysis performed in Parente et al. (2016) detected 16 most significant spatio-temporal clusters within the two study periods for the three different fire size classes. In the first period (Figure 3 top panel), the number of clusters is similar but their size and duration tend to be higher in the south than in the north. The largest cluster is located in the south and while its duration decreases with the increase of BA, its spatial dimension increases. In the second period and for the two first BA classes (Figure 3 bottom panel), the number of clusters increases with BA and their duration increases from north to south. Although the duration of the south clusters is almost the same, their spatial dimension decreases with the increase of BA. The largest BA class of the second period contain only 2 clusters above Tagus River on the west coast, which are very different in duration, but very similar in the spatial dimension.

LULCC statistics computed for clusters areas (CA) unveil that the fraction of total LULCC in the country inside the CA ranges between $44 \%$ and $64 \%$ in the first period $(2000-2007)$ and between $49 \%$ and $65 \%$ in the second (2006 - 2013). Apparently, statistics for smaller (BA<100 ha) FF differ from larger $\mathrm{FF}(\mathrm{BA} \geq 100 \mathrm{ha})$. For the former, LULCC in the CA ranges between $44 \%$ and $47 \%$ in the first period and between $60 \%$ and $65 \%$ in the second, while for the later class, the LULCC ranges are nearly the opposite (64\% and $49 \%$ in the first and second periods). A similar pattern is observed for BA CLCC. For smaller fires, the range is $17 \%-28 \%$ in the first period and $68 \%-69 \%$ in the second while, for larger FF, BA $\cap$ CLCC is more similar (55\% and $49 \%)$ in both periods.

It should also be noted that for small fires ( 5 ha $\leq \mathrm{BA}<15$ ha) CLC the class with more LULCC

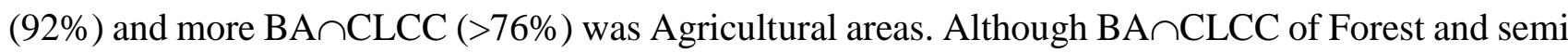
natural areas inside FFs clusters only represents $26 \%$ of total on the first period, in the second period 
it increased to $68 \%$. For this BA class, annual statistics reveal that $56 \%$ of BA $\cap$ CLCC for the period $2000-2007$ happened on the first three years, while for $2006-2013$ period $76 \%$ of BAคCLCC occurred between 2009 and 2012.

For the medium size class $(15 \mathrm{ha} \leq \mathrm{BA}<100 \mathrm{ha})$ Agricultural areas was also the CLC class with

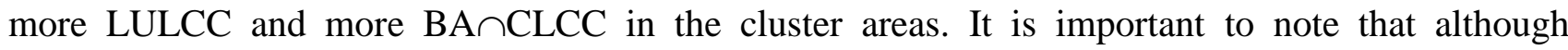
$\mathrm{BA} \cap \mathrm{CLCC}$ of Forest and semi natural areas inside FFs clusters only represent $16 \%$ of total on the first period, in the second period it increased to $68 \%$. Annual statistics for this BA class reveal that $52 \%$ of BA $\cap$ CLCC in the 2000 - 2007 period occurred between 2003 and 2005 while, $65 \%$ of $2006-2013$ period occurred between 2009 and 2012. For the class of the largest FF (BA $\geq 100$ ha) 93\% of the

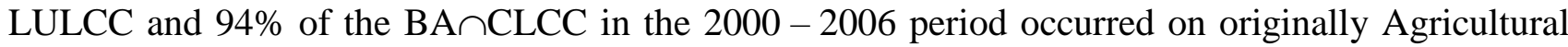
areas while these ratios change, respectively, to $4 \%$ and $19 \%$ in the second period. It is important to point out that in this last period, the CLC class with more LULCC and BA $\cap$ CLCC in the clusters' areas were Forest and semi natural areas. Annual statistics for this BA class express that $81 \%$ of

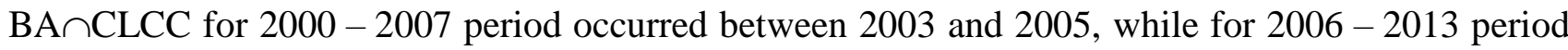
53\% were between 2009 and 2012.

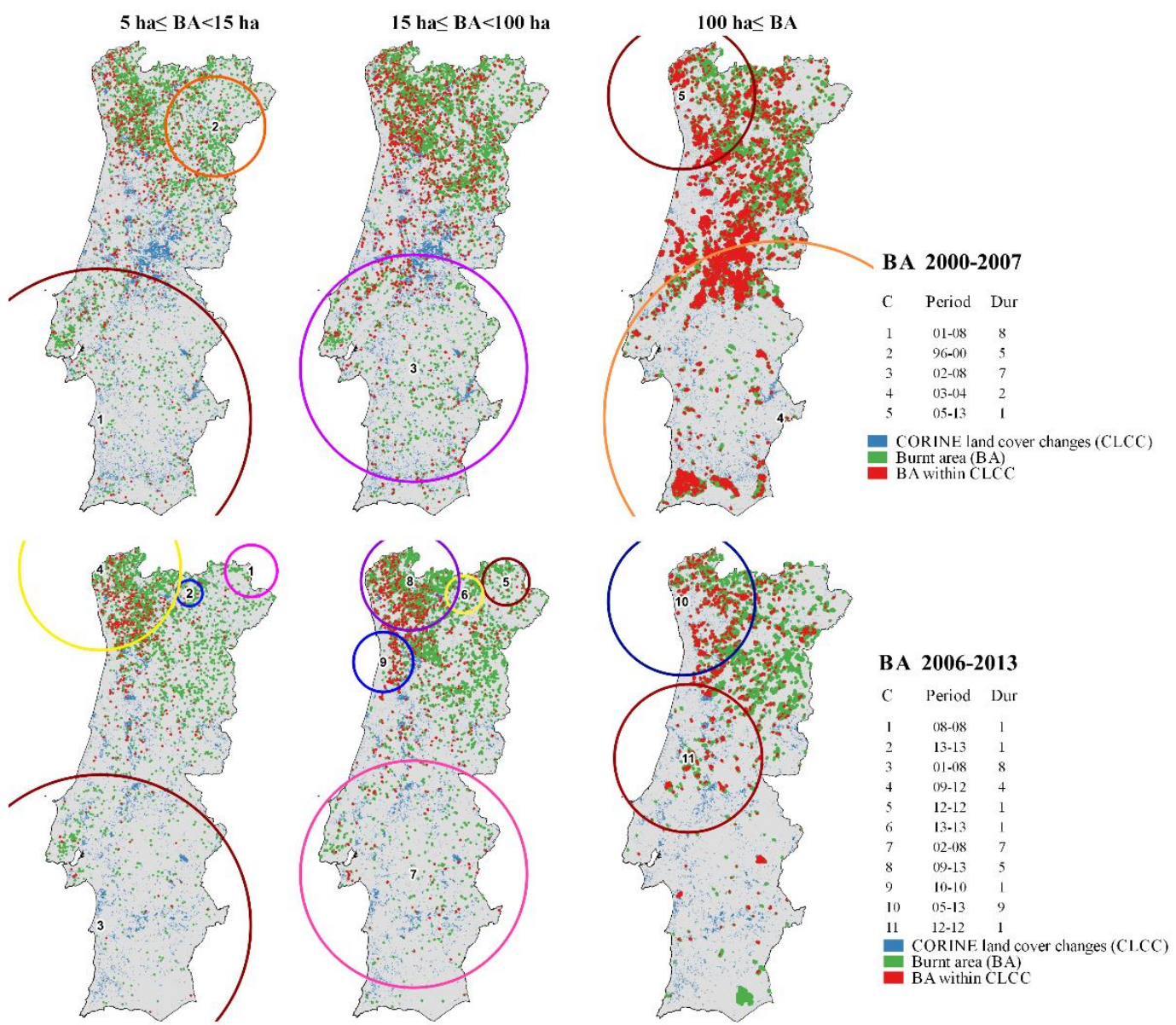

Figure 3 - CORINE land cover changes (CLCC) inventories, Burnt area (BA) and BA included within the CLCC in the periods 2000 - 2007 (top panel) and 2006 - 2013 (bottom panel). Circles $(C)$ represent the most significant spacetime clusters (p-value $<0.01 \%$ ) detected on the National Mapping Burnt Areas for forest fires within the same frame periods.

Finally, it is important to note that the CLCC from Agriculture areas were mostly to Forest and semi natural areas with the exception on the second period of the two lower FF classes, where the change to another different Agriculture areas were more noticeable. Another finding is that the CLCC of Forest and semi natural areas and Artificial surfaces were mostly to a subclass of these CLC. 


\section{Discussion and Conclusions}

This research provides a quantitative assessment of the relationship between LULCC and FFs in Portugal. Our results disclose that in $2000-2013$ period only $10 \%$ of CLC change every six years, and that the intersection of these areas with BA is decreasing in time. In the study period, Forest and semi natural areas was the CLC class with more BA (52\% and $21 \%$ of total annual BA in each period). The LULCC were uniformly distributed in the second period $(2007-2013)$ but concentrated in central areas, which should be a consequence of the impressive BA of 2003.

Cluster analysis has detected 5 and 11) significant spatio-temporal clusters of FF of different sizes in the first and second frame period, respectively. About $45 \%$ of LULCC and $63 \%$ of BA $\cap$ CLCC occurred in the cluster areas of smaller FF ( 5 ha $\leq$ BA $<100$ ha) during the first $(2000-2007)$ and second (2006 - 2013) periods, respectively. However, the proportions are reversed in the case of largest $\mathrm{FF}(\mathrm{BA} \geq 100 \mathrm{ha})$. $\mathrm{BA} \cap \mathrm{CLCC}$ is less than $30 \%$ for small and medium FF in the first period but significantly increases to about $70 \%$ in the second period. BA $\cap$ CLCC for largest FF slightly decrease (55\% to $49 \%$ ) from the first to the second periods.

FFs events were divided into 3 BA classes of different size. For all these classes, Agricultural areas was the CLC class with more LULCC and more BA $\cap C L C C$, with the exception on the second period in largest BA class where Forest and semi natural areas prevail. Annual statistics of BA indicates that, for medium and large FFs, BA $\cap$ CLCC in the first period is highly dependent with what happened in the 2003-2005 period, increasing from 56\% to $81 \%$ from medium to large FFs. This may be due to the extremely severe years of 2003 and 2005, when a devastating sequence of medium and large FFs were observed and reached more than 440,000 ha and more than 250,000 ha of BA, respectively (Trigo et al. 2006; Oliveira et al. 2012). The duration of this period and FFs probably affected the type of the transitions of Agriculture areas. Our results reveal that most of the CLCC originally of Agriculture areas were converted in Forest and semi natural areas with the exception on the second period of the two lower classes. The transition Agriculture areas to Forest and semi natural areas may be an effect of the duration of soil heating in the soil properties, structure and its aggregation, which deteriorates with the destruction of organic matter and others proprietaries as $\mathrm{pH}$, nitrogen, sulphur, or potassium (DeBano et al. 1979).

Authors strongly believe that the obtained results contribute to characterize the recent LULCC in Portugal, the role of FFs in those LULCC, can support a better landscape management to reduce related losses of life, property and assets as well as educational events to increase public awareness to the causes and consequences of FF.

\section{Acknowledgements}

This work was prepared in the frame of project FIREXTR - Prevent and prepare society for extreme fire events: the challenge of seeing the "forest" and not just the "trees", co-financed by the European Regional Development Fund (ERDF) through the COMPETE 2020 - Operational Program Competitiveness and Internationalization (POCI Ref: 16702) and national funds by FCT-Portuguese Foundation for Science and Technology (FCT Ref: PTDC/ATPGEO/0462/2014. The study was also supported by Project Interact - Integrative Research in Environment, Agro-Chain and Technology, NORTE-01-0145-FEDER-000017, research line BEST, co-funded by FEDER/NORTE 2020.

\section{References}

Amato F, Tonini M, Murgante B, Kanevski M (2018) Fuzzy definition of Rural Urban Interface: An application based on land use change scenarios in Portugal. Environmental Modelling \& Software 104, 171-187. 
Amraoui M, Pereira MG, DaCamara CC, Calado TJ (2015) Atmospheric conditions associated with extreme fire activity in the Western Mediterranean region. Science of the Total Environment 524, 32-39.

Bastos A, Gouveia CM, DaCamara CC, Trigo RM (2011) Modelling post-fire vegetation recovery in Portugal. Biogeosciences 8, 3593.

DeBano LF, Rice RM, Eugene CC (1979) Soil heating in chaparral fires: effects on soil properties, plant nutrients, erosion, and runoff. Res Paper PSW-RP-145 Berkeley, CA: US Department of Agriculture, Forest Service, Pacific Southwest Forest and Range Experiment Station 21 p 145,.

Gouveia CM, Bastos A, Trigo RM, DaCamara CC (2012) Drought impacts on vegetation in the preand post-fire events over Iberian Peninsula. Natural Hazards and Earth System Sciences 12, 31233137.

Kanevski M, Pereira MG (2017) Local fractality: The case of forest fires in Portugal. Physica A: Statistical Mechanics and its Applications 479, 400-410.

Oliveira SL, Pereira JM, Carreiras JM (2012) Fire frequency analysis in Portugal (1975-2005), using Landsat-based burnt area maps. International Journal of Wildland Fire 21, 48-60.

Parente J, Pereira MG, Amraoui M, Fischer EM (2018) Heat waves in Portugal: Current regime, changes in future climate and impacts on extreme wildfires. Science of The Total Environment 631, 534-549.

Parente J, Pereira MG, Amraoui M, Tedim F (2018) Negligent and intentional fires in Portugal: spatial distribution characterization. Science of the Total Environment 624, 424-437.

Parente J, Pereira MG, Tonini M (2016) Space-time clustering analysis of wildfires: The influence of dataset characteristics, fire prevention policy decisions, weather and climate. Science of the Total Environment 559, 151-165.

Pereira MG, Aranha J, Amraoui M (2014) Land cover fire proneness in Europe. Forest Systems 23, 598-610.

Pereira MG, Caramelo L, Orozco CV, Costa R, Tonini M (2015) Space-time clustering analysis performance of an aggregated dataset: The case of wildfires in Portugal. Environmental Modelling \& Software 72, 239-249.

Pereira MG, Trigo RM, da Camara CC, Pereira JM, Leite SM (2005) Synoptic patterns associated with large summer forest fires in Portugal. Agricultural and Forest Meteorology 129, 11-25.

Rubel F, Kottek M (2010) Observed and projected climate shifts 1901-2100 depicted by world maps of the Köppen-Geiger climate classification. Meteorologische Zeitschrift 19, 135-141.

San-Miguel-Ayanz J, Durrant TH, Boca R, Libertá G, Boccacci F, Di Leo M, Pérez JL, Schulte E, Benchikha A, Abbas M (2016) Forest fires in Europe, Middle East and North Africa 2015.

Tedim F, Leone V, Amraoui M, Bouillon C, Coughlan M, Delogu G, Fernandes PM, Ferreira C, McCaffrey S, McGee T, Parente J, Paton D, Pereira MG, Ribeiro L, Viegas D, Xanthopoulos G (2018) Defining Extreme Wildfire Events: Difficulties, Challenges, and Impacts. Fire 1, 9. doi:10.3390/fire1010009.

Tonini M, Parente J, Pereira M (2018) Global assessment of land cover changes and rural-urban interface in Portugal. Natural Hazards Earth System Sciences 18, 1647-1664. doi:10.5194/nhess18-1647-2018.

Trigo RM, Pereira J, Pereira MG, Mota B, Calado TJ, Dacamara CC, Santo FE (2006) Atmospheric conditions associated with the exceptional fire season of 2003 in Portugal. International Journal of Climatology 26, 1741-1757. 